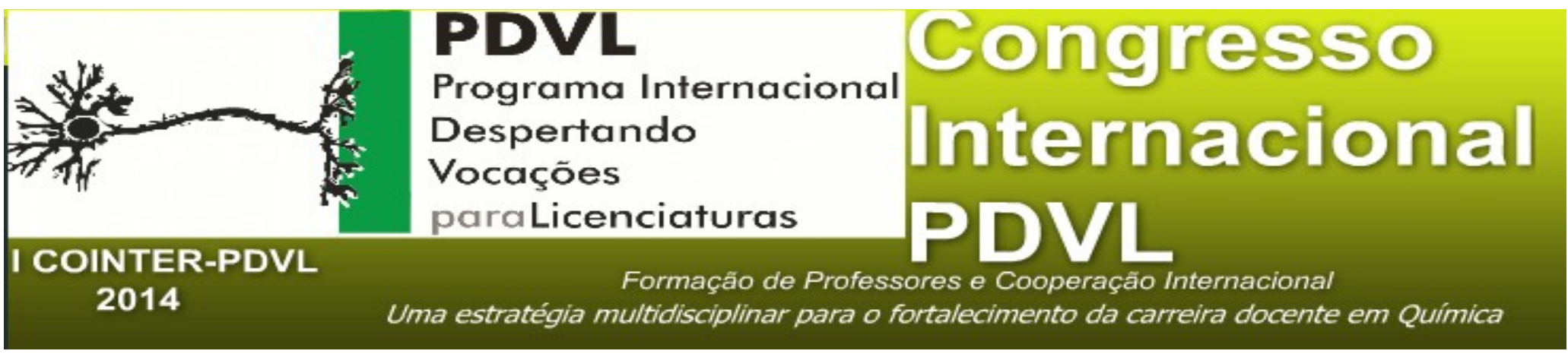

\title{
PERCEPÇÃO DE PROFESSORES E ALUNOS ACERCA DA CARREIRA DOCENTE
}

\author{
Apresentação: Pôster
}

Cíntia de Abreu Arruda ${ }^{1}$; Eliemerson de Souza Sales ${ }^{2}$; Maria Tatiana da Silva Santos ${ }^{3,}$ Kilma da Silva Lima Viana ${ }^{4}$

\section{Introdução}

Diante das transformações sociais, percebe-se a crescente necessidade de profissionalização em diversas áreas do conhecimento, na perspectiva de atender aos anseios da sociedade. Ressaltamos a formação de professor, que em diversas pesquisas apresentam grande índice de evasão e pouca procura pelos cursos ofertados nessa área, enfatizando ainda a carência de profissionais no que se refere a área de Ciências da Natureza em específico da Química.

De acordo com Ferreira (2004. p, 4),

O magistério continua enfrentando um processo intenso de perda de prestígio e status social manifestado, sobretudo, pela rejeição que a carreira enfrenta entre os mais jovens que não a consideram uma boa opção, sobretudo em razão do que consideram "baixa remuneração" e ausência de "perspectivas de futuro".

Neste sentido, com a intenção de solucionar a carência de profissionais da educação, e habilitados nesta área do conhecimento uma das ações do governo, há mais de cinquenta anos, é o investimento no Ensino Superior para ampliar e melhorar os cursos de licenciatura. Porém, ser

1 Graduando em Licenciatura em Química/IFPE /GEPEC /cintiaarruda@outlook.com

2 Graduando em Licenciatura em Química/IFPE /GEPEC/eliemersonsales@gmail.com

3 Graduando em Licenciatura em Química/IFPE/GEPEC/mariatatiana015@hotmail.com

4 Doutoranda em Ensino das Ciências/UFRPE/GEPEC/kilma.viana@vitoria.ifpe.edu.br 
professor já foi o sonho de muitas crianças e jovens, mas, hoje com a desvalorização da profissão no que se refere às condições de trabalho e falta de reconhecimento financeiro, tem-se observado que apresenta-se como uma das profissões menos almejadas.

Diante do exposto, esta pesquisa buscou investigar as concepções de professores de Química acerca dos principais motivos que levam à falta de interesse por parte de estudantes do Ensino Médio pela carreira docente em Química, como também identificar as percepções do estudante acerca da carreira docente nesta área. Compreende-se que o tema abordado nesta pesquisa é de grande relevância, visto que, a superação da carência de profissionais qualificados e atuantes no Ensino de Química, nas escolas públicas, é um dos desafios a serem superados no âmbito educacional.

\section{Fundamentação Teórica}

Historicamente, a escolha da carreira profissional sempre esteve relacionada aos aspectos sociais, culturais e econômicos. A Fundação Carlos Chagas (2010), em seu relatório preliminar acerca da atratividade da carreira docente no Brasil, que teve como objetivo investigar a atratividade da carreira docente sob a ótica de alunos concluintes do ensino médio, destaca que “o processo de escolha profissional e a inserção no mundo do trabalho são cada vez mais intrincados, e geram dilemas, pois remete às questões socioeconômicas e culturais de um país em um dado momento" (p. 9).

Torna-se importante destacar, que além da baixa procura pela carreira docente, os índices de evasão nos cursos de formação de professores têm aumentado significativamente nos últimos anos. Segundo Silva (2011. p, 8)

No início do ano de 2010, o Censo da Educação Superior mostra que o Brasil forma cada vez menos professores. As maiores quedas de 2006 para 2007 foram nas áreas de Letras (-10\%), Geografia (-9\%), Química (-7\%) e Filosofia $(-5 \%)$. Em números absolutos, foram 3,3 mil formandos a menos no período; a redução ocorreu pelo segundo ano consecutivo. Em 2007, 70.507 pessoas formaram-se em Licenciatura, 4,5\% a menos que em 2006 e 9,3\% a menos que em 2005. O dado apenas faz agravar uma situação que já é preocupante.

Percebe-se, que a questão da remuneração é um dos principais problemas que afetam as escolhas pelas carreiras relacionadas à educação no Brasil, e isso faz com que cada vez mais, as pessoas busquem menos a profissionalização nas áreas educacionais.

Justifica-se que, uma das possíveis causas, e consideradas por muitos como principal para esta realidade atual, seja os baixos salários pagos. No Brasil, o salário médio de um professor em início de carreira é um dos menores salários pagos: precisamente, é o antepenúltimo da lista dos mais baixos entre os 38 países pesquisados (RUIZ; RAMOS; HINGEL, 2007). 
Outro fator que pode ser destacado e que faz com que a profissão docente tenha se tornado uma das menos procuradas, é o fato de que muitas pessoas exercem a docência sem formação específica e preparo profissional, ou com preparo precário (FERREIRA, 2004). Essa situação contribuiu para a base do estereótipo de que “qualquer um” pode ser professor, isso faz com que a profissão não seja valorizada.

Segundo a Fundação Carlos chagas (2010) esse déficit também está relacionado a "taxas de vacância”, normalmente avaliadas pelo número de vagas de professor não preenchidas nas escolas e pelo número de vagas “difíceis” de preencher; e, a "escassez oculta”, que se registram quando o ensino é exercido por pessoas não plenamente qualificadas a ensinar para determinado nível escolar ou disciplina.

Considera-se também o envelhecimento da força de trabalho docente: a proporção de docentes próximos da aposentadoria. Ou seja, já estamos com uma enorme escassez de professores, e se não forem desenvolvidas ações mobilizadoras para diminuir essa taxa de falta de professores no Brasil, ficaremos sem professores para exercer, ao que parece, a “árdua” tarefa do ensinar. Logo, deve-se pensar em formas de atrair os jovens de hoje para a área da docência e manter os bons professores atuantes.

De acordo com a presente realidade, fica evidente que os órgãos regulamentadores da Educação Brasileira assim como os Sindicatos que estão à frente das lutas pelo bem da coletividade representada, precisam atuar de forma colaborativa, na perspectiva de contribuir para uma educação pública de qualidade social para os segmentos populares, para a luta por melhores condições de trabalho e de salário, pela formação inicial e continuada para os profissionais da educação, pela dignificação da profissão docente e pelo seu reconhecimento social.

Essa é uma questão importante, pois o desenvolvimento social e econômico depende da qualidade da escolarização básica, mais ainda na emergência da chamada sociedade do conhecimento. Depende, portanto, dos professores no seu trabalho com as crianças e jovens nas escolas.

Em Pernambuco, tem sido desenvolvidas estratégias para o despertar do interesse dos estudantes para as carreiras docente, a partir do Programa Internacional Despertando Vocações para Licenciaturas, promovido pelo Instituto Federal de Pernambuco, em parceria com os Institutos de Alagoas e Paraíba e da Universidad de La Plata (Argentina) e para isso, são consideradas as concepções dos professores e estudantes. Esse programa poder ser um veículo de mudança para essa situação apresentada.

\section{Metodologia}


Essa pesquisa apresentou uma abordagem qualitativa, com o objetivo de investigar as concepções de professores de Química acerca dos principais motivos que levam a falta de interesse por parte de estudantes do Ensino Médio pela carreira docente em Química, assim como identificar as percepções dos estudantes acerca da carreira docente em Química.

Os sujeitos desta pesquisa foram três $(\mathrm{n}=3)$ professores de Química de duas Escolas Públicas localizadas no Município de Orobó - Pernambuco e quinze (n=15) estudantes do Ensino Médio de escolas variadas, ou seja, realidades diferentes.

Para coleta de dados, foram utilizados questionários que, em suma, buscavam identificar as concepções dos professores acerca da carreira docente e quais os principais motivos que levam a falta de interesse dos estudantes pela carreira docente em Química. Aos estudantes foram também aplicados questionários com a perspectiva de identificar como os mesmos percebem a carreira docente em Química.

\section{Resultados e Discussões}

A partir das respostas obtidas, através dos questionários utilizados para coleta dos dados, necessários para discussão desta pesquisa, pôde-se observar que os professores afirmam que a dificuldade de compreensão dos conceitos químicos por parte dos estudantes está relacionada à falta de iniciação dessa área em séries anteriores ao Ensino Médio, acarretando na dificuldade de aprendizagem quando vivenciam os conteúdos de Química do $1^{\circ}$ ano do Ensino Médio.

Segundo o professor (P1), “as noções de Química deveriam ser vivenciadas no $9^{\circ}$ ano do Ensino Fundamental. Os alunos ingressam no Ensino Médio sem a base necessária para a compreensão da disciplina no $1^{\circ}$ ano e nas séries posteriores”.

Observou-se ainda, que os professores apresentam dificuldades de relacionar os conteúdos abordados em sala de aula com o cotidiano dos estudantes, alegando desta forma, que existem conteúdos que se distanciam da realidade dos estudantes, sendo este um obstáculo para o processo de ensino e aprendizagem. Segundo o professor (P3), “tem momentos em que a aplicação de algum tema não é tão próximo do cotidiano do aluno, dificultando assim no processo de ensino e aprendizagem”.

No que se refere às concepções dos professores acerca da carreira docente em Química e como os estudantes percebem esta profissão, o professor (P2) afirma que "a carreira docente em Química é repleta de desafios, primeiramente é tentar mudar a percepção equivocada dos alunos sobre a disciplina, mostrando todas as suas positividades e aplicações; e conviver com os poucos recursos que o sistema público oferece.”

Em relação à existência de incentivo aos estudantes para a escolha da carreira docente, o 
professor (P3) afirma existir, mesmo que a remuneração não seja tão desejada por todos e também devido à desvalorização através da forma das condições de trabalho. Segundo o professor (P3), “a carreira docente mesmo com a desvalorização por parte de salários e em relação às condições de trabalho, não podemos deixar de incentivar os jovens a se interessarem por essa área, que está diante de enorme carência de profissionais, especificamente em Química, pois o professor de Química é fundamental para a divulgação e promoção dos diversos temas abordados pela Química”.

Ainda, torna-se imprescindível destacar a formação dos professores sujeitos desta pesquisa: P1 possui formação em Biologia, P2 em Biologia e P3 em Matemática. É um dado que corrobora para a falta de interesse dos estudantes pelo aprendizado, consequentemente pela carreira docente, visto que a formação destes professores não os permite a utilização de práticas que proporcionem ao processo de ensino e aprendizagem a dinâmica necessária para despertar o interesse dos estudantes a participarem de forma ativa e terem curiosidade pela profissão.

De acordo com os estudantes, 80\% afirmaram considerar a disciplina de Química de difícil compreensão, e este motivo, segundo eles, está relacionado à forma como o professor ensina os conteúdos da Química, pois, na maioria das vezes, o conhecimento é resumido à memorização.

Outro fator, está na falta de contextualização, pois para eles o conteúdo tem que fazer sentido para estudarem e, quando não vêem nenhuma relação com o cotidiano, não faz sentido algum. Também o que colabora para a disciplina ser considerada de difícil compreensão é a desvinculação da teoria e prática dos conteúdos, pois, segundo um dos estudantes, a teoria e prática na Química andam juntas.

Porém, nem todas as escolas possuem laboratórios e, quando possui, faltam materiais necessários para a realização dos experimentos, o que colabora para a ausência de aulas práticas. Logo, esses aspectos elencados, fazem com que os estudantes não tenham desejo de seguir a carreira docente, mesmo afirmando que a carreira docente é de grande importância na vida de qualquer cidadão, que é uma das melhores carreiras, devido ao fato de que toda profissão passa pelo professor, mas a desvalorização apontada por eles faz com que os estudantes hoje escolham outras áreas.

\section{Conclusões}

Diante do exposto, foi observado que os fatores para não escolha da carreira docente no Brasil estão relacionadas a baixos salários, às condições de trabalho, à formação do professor que ministra a aulas de Química e à prática desenvolvida em sala de aula.

Observamos que os professores pesquisados não tinham formação na área específica da Química, que corrobora com os dados apresentados no capítulo da fundamentação, acerca dos 
estudos sobre os professores de outras áreas que lecionam Química hoje no Brasil, sendo considerado pelos estudantes impactante no processo de ensino-aprendizagem, especialmente com relação ao domínio do conteúdo, à dicotomia teoria e prática e à falta do uso dos laboratórios.

Portanto, esses motivos caracterizam alguns dos motivos pela falta de interesse dos estudantes pela procura da carreira docente, mesmo considerando sua importância e sendo incentivados pelos professores, que buscam mudar a percepção equivocada dos alunos sobre a carreira, mostrando todas as suas positividades e aplicações.

A partir desses resultados, ressaltamos a importância de investimento em novas estratégias para despertar os estudantes para a carreira docente. O Programa Internacional Despertando Vocações, desenvolvidos pelo Instituto Federal de Pernambuco, em parceria com os Institutos Federais de Alagoas e Paraíba e com a Universidad de La Plata (Argentina), pode ser uma dessas estratégias.

\section{Referências}

FERREIRA, R. As expectativas de professores e licenciandos sobre a carreira e remuneração e a pplítica de valorização do trabalho docente no Brasil. In: 27ª Reunião da ANPED, 2004, Caxambu. Anais da $27^{\mathrm{a}}$ Reunião da Anped, 2004. V. 1. P. 45-61

Revista Abril on-line. Atratividade da Carreira docente. Disponível em:http://revistaescola.abril.com.br/pdf/relatorio-final-atratividade-carreira-docente.pdf. $\quad$ Acesso: $30 / 10 / 2014$.

RUIZ, A. I.; RAMOS, M. N.; HINGEL M. Escassez de Professores no Ensino Médio: Propostas estruturais e emergenciais. Brasília. Ministério da Educação, 2007.

SILVA, A. M. Proposta para tornar o Ensino de Química mais atraente. Revista de Química Industrial, Rio de Janeiro, ano 79, n. 731, p. 7-12, 2011. 